\title{
The first Slovak Legius syndrome patient carrying the SPRED1 gene mutation
}

\author{
Martina Sekelska ${ }^{1}$, Lenka Briatkova ${ }^{1}$, Tomas Olcak ${ }^{1}$, Anna Bolcekova ${ }^{2}$, Denisa Ilencikova ${ }^{2}$, \\ Ludevit Kadasi ${ }^{1,3}$ and Andrea Zatkova ${ }^{3}$ \\ ${ }^{1}$ Department of Molecular Biology, Comenius University, Faculty of Natural Sciences, Mlynska dolina, Ilkovicova 6, 84215 \\ Bratislava, Slovakia \\ ${ }^{2}$ 2nd Department of Pediatrics, Comenius University Medical School and Children's University Hospital, Limbova 1, 83340 \\ Bratislava, Slovakia \\ ${ }^{3}$ Institute for Clinical and Translational Research, Biomedical Research Center, Slovak Academy of Sciences, Dubravska \\ cesta 9, 84505 Bratislava, Slovakia
}

\begin{abstract}
Autosomal dominant disorder Legius syndrome (NF1 - like syndrome) shows phenotype features that overlap with neurofibromatosis type 1 (NF1), such as CALMs, freckling, macrocephaly and learning disability. Mutation analysis provides an important tool in order to distinguish two entities that have different clinical implications. We analyzed SPRED1 gene by cDNA and/or gDNA sequencing in a cohort of 46 Slovak patients in whom previously NF1 mutation was excluded. In one case we identified a nonsense mutation c.46C $>\mathrm{T}\left(\mathrm{p} . \operatorname{Arg} 16^{*}\right)$ in exon 2 of SPRED1 gene, confirming diagnosis of Legius syndrome. This mutation was reported previously.
\end{abstract}

Key words: Legius syndrome - SPRED1 - Neurofibromatosis - NF1 - Mutation analysis

\section{Introduction}

Both neurofibromatosis type 1 (NF1, OMIM \#162200) and Legius syndrome (NF1-like syndrome, OMIM \#611431) belong to so called rasopathies, the diseases characterized by mutations in the genes involved in RAS-mitogen-activated protein kinase (RAS-MAPK) pathway (Zenker 2011). The main clinical features of Legius syndrome, such as café au lait macules (CALMs), freckling, macrocephaly and learning disability, overlap with NF1. However, so far no neurofibromas, bone lesions, optical gliomas, Lish nodules, or malignant peripheral nerve sheath tumors were reported in Legius syndrome individuals, while they are rather typical for NF1 (NIH 1988, Brems et al. 2007; Denayer et al. 2008, 2011; Messiaen et al. 2009; Pasmant et al. 2009; Spurlock et al. 2009; Muram-Zborovski et al. 2010; Laycock-van Spyk et al. 2011). NF1 patients usually carry germline mutation within NF1 - one of the largest human genes composed of

Correspondence to: Andrea Zatkova, Institute for Clinical and Translational Research, Biomedical Research Center of Slovak Academy of Sciences, Dubravska cesta 9, 84505 Bratislava, Slovakia E-mail: andrea.zatkova@savba.sk
60 exons (17.q11.2, 280kb). Product of this gene, a tumor supressor protein neurofibromin, plays key role in negative regulation of RAS-MAPK signal pathway, where it functions as inhibitor of Ras via Ras-GTPase domain (Kern and Winter 2006; Stevenson et al. 2008). Instead, Legius syndrom is caused by mutations in SPRED1 (Sprouty-related, EVH1 domain containing 1 ), a small gene (15q13.2, 104.4 kb) (Kato et al. 2003) divided in seven exons that code for 7255bp long transcript and protein monomer of 444 amino acids (Brems et al. 2007). The SPRED1 protein bound to Ras forms an active SPRED-Ras complex, which suppresses Raf phosphorylation and activation, thus, inhibits MAPK signal pathway (Wakioka et al. 2001). Recently it has been shown that SPRED1 inhibits the Ras-ERK pathway by recruiting neurofibromin to Ras through the EVH1-GRD interaction (Hirata et al. 2016).

Previously we analyzed 167 Slovak patients showing symptoms compatible with NF1 for the presence of the NF1 gene mutations by sequencing of the entire NF1 coding region and MLPA analysis (Nemethova et al. 2013). In 46 of them, no NF1 mutation was identified. In present report, we performed SPRED1 gene mutation analysis in these cases. In order to spot also possible untypical Legius syndrome 


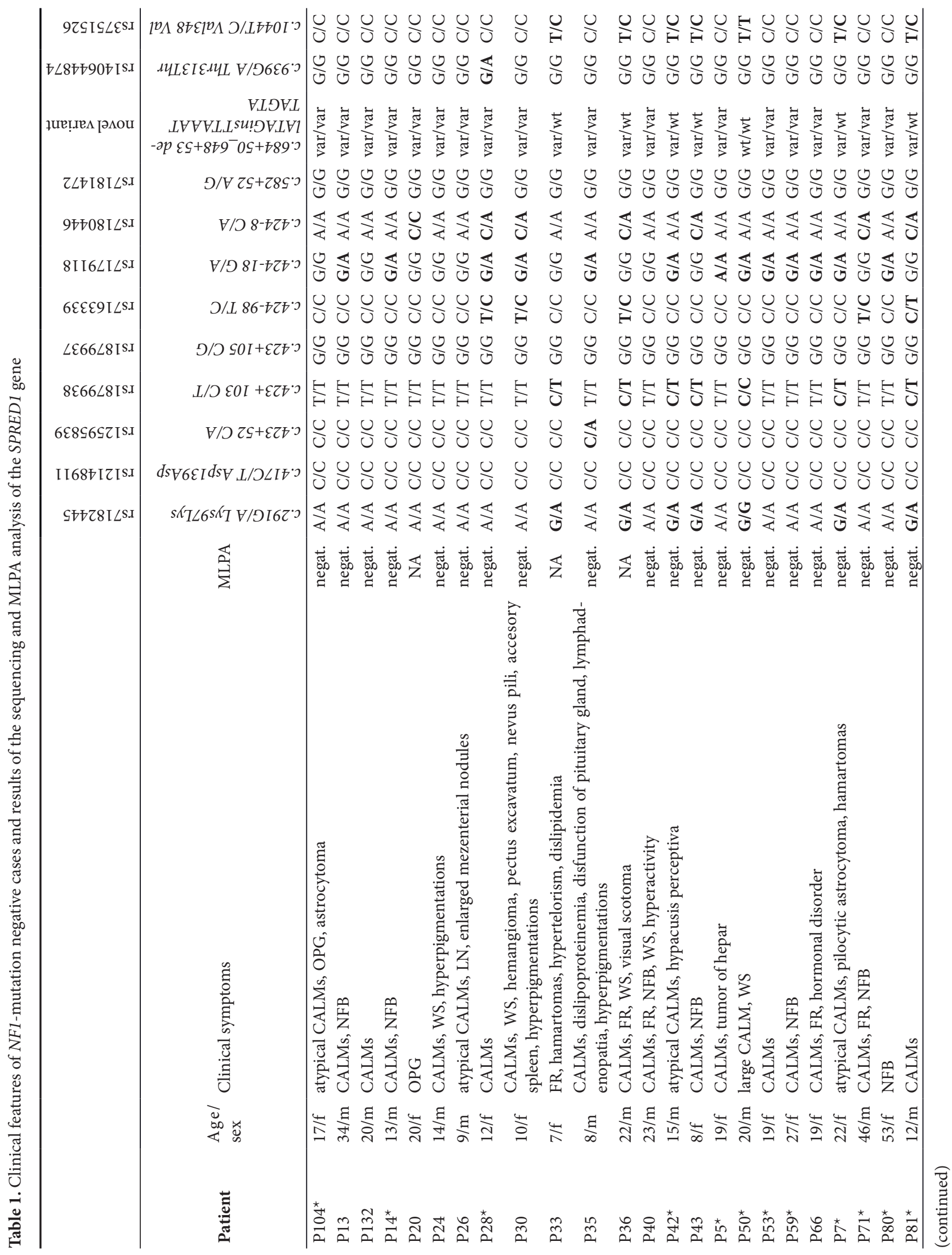




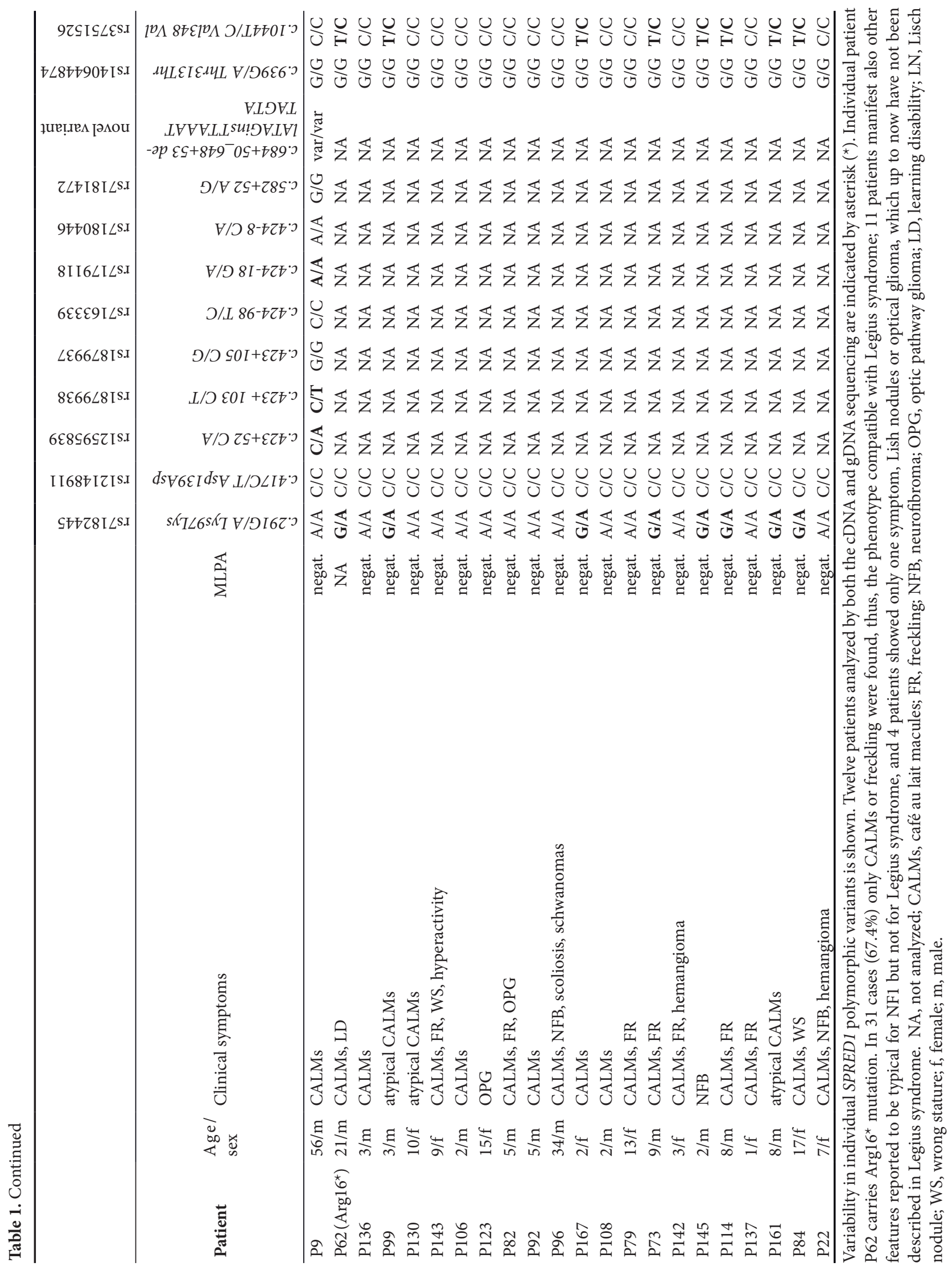


individuals, we analysed all of NF1 mutation-negative cases, irrespective of the clinical indications (Table 1).

\section{Methods}

SPRED1 gene analysis was performed by sequencing of gDNA only (13 cases), cDNA only (21 cases), whereas in 12 patients both gDNA and cDNA was analyzed (Table 1). Direct sequencing was performed employing Big Die ${ }^{\varpi}$ Terminator v3.1 Cycle Sequencing Kit (Applied Biosystems) and genetic analyzer ABI PRISM ${ }^{\circledast} 3130 x l$ (Applied Biosystems). PCR primers are summarized in Supplementary Table S1. SPRED1 reference sequence NM_152594.2 from Ensemble database was used for variant description. In 42 individuals, MLPA analysis was performed using SALSA P295 SPRED1 probemix (MRC Holland).

\section{Results and Discussion}

In patient P62 we identified SPRED1 nonsense mutation c.46C > T (p.Arg16*) (Table 1, Figure 1A) that leads into premature stop codon within EVH1 domain (Figure 1B), thus we report the first genetically confirmed Slovak patient with Legius syndrome. MLPA (multiplex ligation-dependent

A

Patient P62 - SPRED1 gene, exon 2

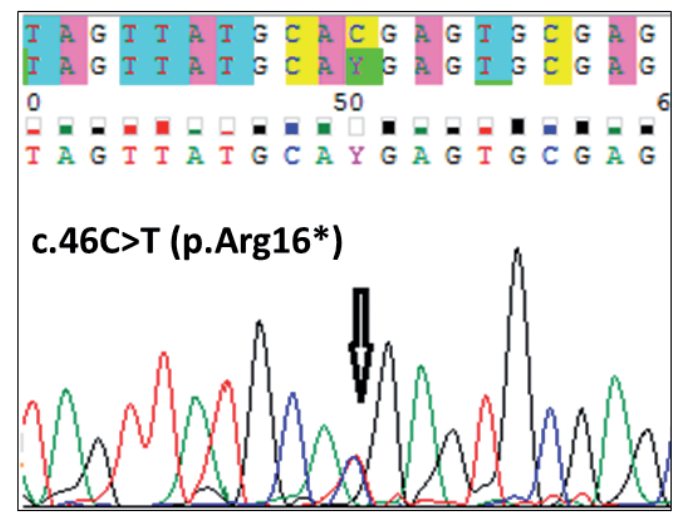

B

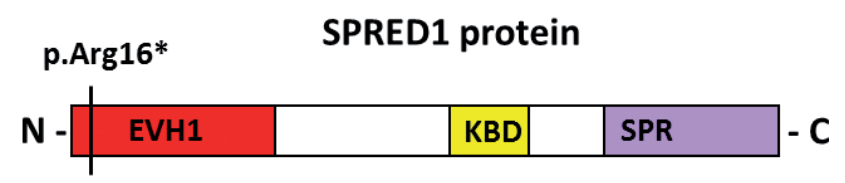

Figure 1. SPRED1 gene mutation identified in patient P62. DNA sequence shows substitution $\mathrm{C}>\mathrm{T}$ at the position 46 within exon 2 of the SPRED1 gene (A), leading into premature stop codon after 16 amino acids within $\mathrm{N}$-terminal EVH1 domain (B). probe amplification analysis) did not show intragenic deletion, duplication or microdeletions in any of the analyzed individuals (Table 1). The incidence of SPRED1 mutations in Slovak cohort of the NF1 mutation-negative cases with NF1 features is $1 / 46(2.17 \%)$. If we take into account only cases with clinical features compatible with Legius syndrome, the number is even higher: $1 / 31$ (3.2\%).

Table 1 summarizes also variability in 11 SNPs already described in dbSNP database and ARUP as well as one novel intronic variant c.684+50_648+53delATAG insTTAAATTAGTA (Table 1) that we found present in 96\% (24/25) of patients in homozygous or heterozygous state. This variant was found also in 4/8 individuals tested for a SPRED1 mutation in Austria (Katharina Wimmer 2015, personal communication).

Although a possible role of tested variants in Legius syndrome has not been shown so far we wanted to compare the allele frequencies in our population to those published elsewhere. We compared the global minor allele frequency (MAF) of the studied variants as indicated in dbSNP database (http://www.ncbi.nlm.nih.gov/projects/SNP/), in NHLBI GO Exome Sequencing Project (ESP) (http://evs. gs.washington.edu/EVS/) to that observed in our cohort of patient (Supplementary Table S2). In our cohort we did not observe presence of minor alleles in variants rs12148911 (c.417C>T, p.Asp139=), rs1879937 (c.423+105C>G) and rs7181472 (c.582+52A $>\mathrm{G})$. The frequency of the minor allele $A$ in variant c. $582+52 \mathrm{~A}>\mathrm{G}$ in our patients was comparable only with prevalence in European population. The occurrence of minor allele in remaining seven polymorphisms in our patients was comparable to global MAF. In one case, $\mathrm{P} 28$, we found the presence of A allele of a rare synonymous variant c.939G $>$ A, p.Thr313= (global frequency 0.06 , Table 1 , Supplementary Table S2).

The first Legius syndrom patient in Slovakia is a 21 years old male, who shows 9 CALMs and learning disability. Mutation $\operatorname{Arg} 16^{*}$ was reported previously in 10 cases who showed freckling, macrocephaly, hypertelorism, and monoblastic acute leukemia together with different number of CALMs (Spurlock et al. 2007, 2009; Messiaen et al. 2009; Pasmant et al. 2009, 2015; Spencer et al. 2011; LOVD database 2015). Thus, there seem to be no correlation between the presence of this mutation and some specific phenotype in the patients.

NF1 but not Legius syndrome patients show increased risk for malignance (Brems et al. 2009). Importance of exact diagnosis is evident in order to choose relevant clinical follow up for individual patients. Since some NF1-specific symptoms develop at advanced age, in young patients the NF1 and SPRED1 mutation analysis can help to distinguish two entities at early stage. If NF1 is confirmed by the presence of the NF1 mutation, it is necessary to monitor the patient by clinical follow up and regular controls. Follow up can be more moderate in Legius syndrome cases instead. 
Interestingly, LOVD and ARUP database mention one patient who shows both NF1 and SPRED1 mutation. This 19 years old man with 8 CALMs and 2 neurofibromas carries NF1 splicing mutation c.5944-2A>G and SPRED1 mutation c.270C $>$ G (p.(His90Gln) (Arup database 2015; LOVD database 2015), thus it is important to perform genetic studies in larger numbers of patient in order to understand the significance of individual variants for clinical manifestations of the disease.

Acknowledgements. This contribution is the result of the projects implementation "Diagnostics of socially important disorders in Slovakia, based on modern biotechnologies" ITMS 26240220058 , "Creating Competitive Centre for research and development in the field of molecular medicine" ITMS 26240220071, and "University Scientfic Park of Comenius University” ITMS 26240220086, supported by the Research \& Developmental Operational Program funded by the ERDF.

Conflict of interest. All authors declare no conflict of interest. We confirm that we have read the Journal's position on issues involved in ethical publication and affirm that this report is consistent with those guidelines.

\section{References}

Brems H., Chmara M., Sahbatou M., Denayer E., Taniguchi K., Kato R., Somers R., Messiaen L., De Schepper S., Fryns J. P. et al. (2007): Germline loss-of-function mutations in SPRED1 cause a neurofibromatosis 1-like phenotype. Nat. Genet. 39, $1120-1126$ https://doi.org/10.1038/ng2113

Brems H., Beert E., de Ravel T., Legius E. (2009): Mechanisms in the pathogenesis of malignant tumours in neurofibromatosis type 1. Lancet Oncol. 10, 508-515 https://doi.org/10.1016/S1470-2045(09)70033-6

Denayer E., Ahmed T., Brems H., Van Woerden G., Borgesius N. Z., Callaerts-Vegh Z., Yoshimura A., Hartmann D., Elgersma Y., D'Hooge R. et al. (2008): Spred1 is required for synaptic plasticity and hippocampus-dependent learning. J. Neurosci. 28, 14443-14449 https://doi.org/10.1523/JNEUROSCI.4698-08.2008

Denayer E., Chmara M., Brems H., Kievit A. M., van Bever Y., Van den Ouweland A. M., Van Minkelen R., de Goede-Bolder A., Oostenbrink R., Lakeman P. et al. (2011): Legius syndrome in fourteen families. Hum. Mutat. 32, E1985-1998 https://doi.org/10.1002/humu.21404

Hirata Y., Brems H., Suzuki M., Kanamori M., Okada M., Morita R., Llano-Rivas I., Ose T., Messiaen L., Legius E. et al. (2016): Interaction between a domain of a negative regulator of the RAS-ERK pathway, SPRED1, and the GTPase-Activating Protein-Related Domain of neurofibromin is implicated in Legius Syndrome and Neurofibromatosis Type 1. J. Biol. Chem. 291, 3124-3134

Kato R., Nonami A., Taketomi T., Wakioka T., Kuroiwa A., Matsuda Y., Yoshimura A. (2003): Molecular cloning of mammalian
Spred-3 which suppresses tyrosine kinase-mediated Erk activation. Biochem. Biophys. Res. Commun. 302, 767-772 https://doi.org/10.1016/S0006-291X(03)00259-6

Kern S. E., Winter J. M. (2006): Elegance, silence and nonsense in the mutations literature for solid tumors. Cancer Biol. Ther. 5, 349-359 https://doi.org/10.4161/cbt.5.4.2551

Laycock-van Spyk S., Jim H. P., Thomas L., Spurlock G., Fares L., Palmer-Smith S., Kini U., Saggar A., Patton M., Mautner V. et al. (2011): Identification of five novel SPRED1 germline mutations in Legius syndrome. Clin. Genet. 80, 93-96 https://doi.org/10.1111/j.1399-0004.2010.01618.x

Messiaen L., Yao S., Brems H., Callens T., Sathienkijkanchai A., Denayer E., Spencer E., Arn P., Babovic-Vuksanovic D., Bay C. et al. (2009): Clinical and mutational spectrum of neurofibromatosis type 1-like syndrome. JAMA 302, 2111-2118 https://doi.org/10.1001/jama.2009.1663

Muram-Zborovski T. M., Stevenson D. A., Viskochil D. H., Dries D. C., Wilson A. R., Rong M. (2010): SPRED 1 mutations in a neurofibromatosis clinic. J. Child Neurol. 25, 1203-1209 https://doi.org/10.1177/0883073809359540

Nemethova M., Bolcekova A., Ilencikova D., Durovcikova D., Hlinkova K., Hlavata A., Kovacs L., Kadasi L., Zatkova A. (2013): Thirty-nine novel neurofibromatosis 1 (NF1) gene mutations identified in Slovak patients. Ann. Hum. Genet. 77, 364-379 https://doi.org/10.1111/ahg.12026

NIH (1988): Neurofibromatosis. Conference statement. National Institutes of Health Consensus Development Conference. Arch. Neurol. 45, 575-578

Pasmant E., Sabbagh A., Hanna N., Masliah-Planchon J., Jolly E., Goussard P., Ballerini P., Cartault F., Barbarot S., LandmanParker J. et al. (2009): SPRED1 germline mutations caused a neurofibromatosis type 1 overlapping phenotype. J. Med. Genet. 46, 425-430 https://doi.org/10.1136/jmg.2008.065243

Pasmant E., Parfait B., Luscan A., Goussard P., Briand-Suleau A., Laurendeau I., Fouveaut C., Leroy C., Montadert A., Wolkenstein P. et al. (2015): Neurofibromatosis type 1 molecular diagnosis: what can NGS do for you when you have a large gene with loss of function mutations? Eur. J. Hum. Genet. 23, 596-601 https://doi.org/10.1038/ejhg.2014.145

Spencer E., Davis J., Mikhail F., Fu C., Vijzelaar R., Zackai E. H., Feret H., Meyn M. S., Shugar A., Bellus G. et al. (2011): Identification of SPRED1 deletions using RT-PCR, multiplex ligation-dependent probe amplification and quantitative PCR. Am. J. Med. Genet. A 155A, 1352-1359 https://doi.org/10.1002/ajmg.a.33894

Spurlock G., Griffiths S., Uff J., Upadhyaya M. (2007): Somatic alterations of the NF1 gene in an NF1 individual with multiple benign tumours (internal and external) and malignant tumour types. Fam. Cancer 6, 463-471

https://doi.org/10.1007/s10689-007-9149-5

Spurlock G., Bennett E., Chuzhanova N., Thomas N., Jim H. P., Side L., Davies S., Haan E., Kerr B., Huson S. M. et al. (2009): SPRED1 mutations (Legius syndrome): another clinically useful genotype for dissecting the neurofibromatosis type 1 phenotype. J. Med. Genet. 46, 431-437 
https://doi.org/10.1136/jmg.2008.065474

Stevenson D. A., Swensen J. J., Viskochil D. H. (2008): Neurofibromatosis type 1 and other syndromes of the Ras pathway. In Neurofibromatoses (Ed. D. Kaufman), pp. 32-45, Basel, Karger https://doi.org/10.1159/000126503

Wakioka T., Sasaki A., Kato R., Shouda T., Matsumoto A., Miyoshi K., Tsuneoka M., Komiya S., Baron R., Yoshimura A. (2001): Spred is a Sprouty-related suppressor of Ras signalling. Nature 412, 647-651 https://doi.org/10.1038/35088082

Zenker M. (2011): Clinical manifestations of mutations in RAS and related intracellular signal transduction factors. Curr. Opin. Pediatr. 23, 443-451

https://doi.org/10.1097/MOP.0b013e32834881dd

Received: May 2, 2016

Final version accepted: November 11, 2016

First published online: February 2, 2017 


\section{The first Slovak Legius syndrome patient carrying the SPRED1 gene mutation}

Martina Sekelska ${ }^{1}$, Lenka Briatkova ${ }^{1}$, Tomas Olcak $^{1}$, Anna Bolcekova ${ }^{2}$, Denisa Ilencikova ${ }^{2}$, Ludevit Kadasi ${ }^{1,3}$ and Andrea Zatkova ${ }^{3}$

${ }^{1}$ Department of Molecular Biology, Comenius University, Faculty of Natural Sciences, Mlynska dolina, Ilkovicova 6, 84215 Bratislava, Slovakia

2 2nd Department of Pediatrics, Comenius University Medical School and Children's University Hospital, Limbova 1, 83340 Bratislava, Slovakia

${ }^{3}$ Institute for Clinical and Translational Research, Biomedical Research Center, Slovak Academy of Sciences, Dubravska cesta 9, 84505 Bratislava, Slovakia

\section{Supplementary Tables}

Table S1. List of the PCR primers used for amplification and sequencing of the individual SPRED1 exons and short flanking intronic sequences from patients' gDNA, as well as of the coding region fragments from $\mathrm{cDNA}$

\begin{tabular}{|c|c|c|}
\hline \multicolumn{2}{|c|}{$\begin{array}{l}\text { Amplified region and size of the } \\
\text { PCR product }\end{array}$} & \multirow{2}{*}{\begin{tabular}{|l} 
Primer sequence \\
GGTACCGTTCTGGGTGAGG
\end{tabular}} \\
\hline \multirow{2}{*}{ Exon 1 (269bp) } & $\mathrm{F}$ & \\
\hline & $R$ & AAGTTTCGGATGGGTCTGG \\
\hline \multirow{2}{*}{ Exon2 (431bp) } & $\mathrm{F}$ & AAACACCTTAGTCACCACATGTTA \\
\hline & $R$ & TGCCTTTAACACAGAAACAGC \\
\hline \multirow{2}{*}{ Exon3 (398bp) } & $\mathbf{F}$ & AGCGTTGTATCACCTCAGTTTG \\
\hline & $\mathrm{R}$ & TGAGGTTTCAAAGCCTGGTC \\
\hline \multirow{2}{*}{ Exon4 (340bp) } & $\mathbf{F}$ & TTAATTGCCAGGCAGTCCAG \\
\hline & $\mathbf{R}$ & ATGAGGGATGCTCAACCTGT \\
\hline \multirow{2}{*}{ Exon5 (398bp) } & $F$ & CATTTGAGTTTTGGGAATTGCT \\
\hline & $\mathbf{R}$ & CATTTGAGTTTTGGGAATTGCT \\
\hline \multirow{2}{*}{ Exon6 (396bp) } & $\mathbf{F}$ & CATTTGAGTTTTGGGAATTGCT \\
\hline & $\mathbf{R}$ & CATTTGAGTTTTGGGAATTGCT \\
\hline \multirow{2}{*}{ Exon7a (552bp) } & F1 & CATTTGAGTTTTGGGAATTGCT \\
\hline & R1 & CATTTGAGTTTTGGGAATTGCT \\
\hline \multirow{2}{*}{ Exon7b(569BP) } & F2 & AGACGCAGCCTTCCTCATTA \\
\hline & $\mathrm{R2}$ & AGTTAGGCATGGCGTGAAAC \\
\hline \multirow{2}{*}{ CDNA FR1 (382bp) } & $1 \mathrm{~F}$ & CTGCTGTTGCTCCTCCATCT \\
\hline & $1 \mathrm{R}$ & AAAAGCCCTAGCATCAGCAG \\
\hline \multirow{2}{*}{ CDNA FR2 (353bp) } & $2 \mathrm{~F}$ & CTGCTGATGCTAGGGCTTTT \\
\hline & $2 \mathrm{R}$ & TAGGCTTCCACATTCCTTGG \\
\hline \multirow{2}{*}{ CDNA FR3 (667bp) } & $3 F^{*}$ & CCAAAATAGGGTCCCTTTGA \\
\hline & $3 \mathrm{R}^{*}$ & ACCATTTCATCCAGCAGCTT \\
\hline
\end{tabular}

PCR primers and conditions were described by Brems et al. (2007) except for one pair designed by us (3F and 3R, labelled by asterisk $\left.{ }^{\star}\right)$. Primers used for PCR amplification of individual exons/fragments were used also for direct sequencing. 
Table S2. Comparison of a global minor allele frequency (MAF) of the selected variants as indicated in different databases and identified by us

\begin{tabular}{|c|c|c|c|c|c|c|c|c|c|c|c|c|}
\hline Variant & $\begin{array}{l}\text { c.291G/A } \\
\text { Lys97= }\end{array}$ & $\begin{array}{l}\text { c.417C/T } \\
\text { Asp139= }\end{array}$ & $\begin{array}{c}\text { c. } 423+52 \\
\text { C/A }\end{array}$ & $\begin{array}{c}c .423+103 \\
C / T\end{array}$ & $\begin{array}{c}\text { c. } 423+105 \\
\text { C/G }\end{array}$ & $\begin{array}{c}\text { c. } 424-98 \\
\text { T/C }\end{array}$ & $\begin{array}{c}\text { c. } 424-18 \\
\text { G/A }\end{array}$ & c. $424-8 \mathrm{C} / \mathrm{A}$ & $\begin{array}{c}\text { c. } 582+52 \\
\text { A/G }\end{array}$ & $\begin{array}{c}\text { c.684+50 } \\
\text { delATAG } \\
\text { insTTAAATTAG } \\
\text { TA }\end{array}$ & $\begin{array}{l}\text { c.939G/A } \\
\text { Thr313= }\end{array}$ & $\begin{array}{c}\text { c.1044T/C } \\
\text { Val348= }\end{array}$ \\
\hline minor allele & G & $T$ & A & C & C & $T$ & A & C & A & wt & A & $T$ \\
\hline $\begin{array}{l}\text { MAF in our } \\
\text { cohort (\%) }\end{array}$ & 17.39 & 0 & 4 & 18 & 0 & 10 & 32 & 16 & 0 & 16 & 1.08 & 17.39 \\
\hline $\begin{array}{l}\text { MAF according } \\
\text { to project } 1000 \\
\text { Genomes (\%) }\end{array}$ & 19.99 & NA & 8.69 & 20.05 & 4.59 & 20.07 & 17.79 & 20.07 & 9.05 & NA & 0.06 & 20.05 \\
\hline $\begin{array}{l}\text { MAF according } \\
\text { to NHLBI GO } \\
\text { ESP (\%) } \\
\end{array}$ & 17.41 & NA & 2.92 & NA & NA & NA & 25.02 & 17.45 & 9.3 & NA & NA & 17.46 \\
\hline $\begin{array}{l}\text { MAF in } \\
\text { european } \\
\text { population } \\
\text { according to } \\
\text { NHLBI GO ESP } \\
\text { (\%) } \\
\end{array}$ & 10.29 & NA & 4.1 & NA & NA & NA & 25.96 & 10.3 & 0.17 & NA & NA & 10.3 \\
\hline $\begin{array}{l}\text { according to } \\
\text { ARUP }\end{array}$ & benign & NA & NA & NA & NA & NA & NA & benign & NA & NA & benign & benign \\
\hline $\begin{array}{l}\text { according to } \\
\text { dbSNP }\end{array}$ & benign & NA & NA & NA & NA & NA & benign & benign & NA & NA & NA & benign \\
\hline
\end{tabular}

NHLBI GO ESP, NHLBI GO Exome Sequencing Project; MAF, minor allele frequency; ARUP, mutation database; dbSNP, single nucleotide polymorphism database (according to http://www.ncbi.nlm.nih.gov/projects/SNP/, http://evs.gs.washington.edu/EVS/). 